\title{
Living Labbing the Rotterdam Way: Co-Creation as an Enabler for Urban Innovation
}

\author{
Ingrid Mulder
}

\author{
"Living in cities is an art, and we need the vocabulary of art, of style," \\ to describe the peculiar relationship between man and material that \\ exists in the continual creative play of urban living. The city as we \\ imagine it, then, soft city of illusion, myth, aspiration, and \\ nightmare, is as real, maybe more real, than the hard city one can \\ locate on maps in statistics, in monographs on urban sociology and \\ demography and architecture. \\ Jonathan Raban \\ Novelist and travel writer
}

\begin{abstract}
The living lab concept seems appropriate to study the design and evaluation of innovative services that enrich everyday life. This article elaborates on "living methodologies", methods and tools necessary in "living labbing". Living methodologies address the social dynamics of everyday life that are essential for understanding living labs, not only conceptually, but also as mature methodologies for fostering innovation in real-life contexts. We report on three cases from Rotterdam in the Netherlands, where "living labbing" was used to enable citizens to co-develop their city. These cases utilized visual ethnography as a research method and prototyping and co-creating as design tools. The cases not only inspire citizen participation, but also inform social innovation and city's policymaking. The user-driven approach, do-it-yourself mindset, and the participatory character perfectly fit with the down-to-earth attitude of Rotterdam residents.
\end{abstract}

\section{Introduction}

The living lab approach is a research methodology for sensing, prototyping, validating, and refining complex solutions in multiple and evolving real-life contexts. Living labs are user communities that have been mostly used in recent years by high-tech companies for validating new technology applications in real end-user environments. In a living lab, it is crucial to allow for experience research, in-situ research with an emphasis on measuring real-life use, continuous iterations between development and evaluation, and an open innovation consortium involving partners with different backgrounds. In addition, living labs require an open attitude and a human-centred mindset.
A living lab is not just a network of infrastructures and services, but a network of real people with rich experiences and a new way to deal with user-driven innovation. Those experiences are the very things that make a living lab living, and therefore, appropriate methods should capture these social and dynamic aspects (Mulder et al., 2008; tinyurl.com/8su2mal). However, Mulder and Stappers (2009; tinyurl.com/9f75ndh) reviewed methods used in living labs and found an emphasis on the use of traditional methods for laboratory testing over the use of co-creation techniques and participatory methods. Traditional methods have their value in ethnographic research, but they might not exploit living labs as an infrastructure that comes close to the user nor make use of the potential of living labs as a way to 


\title{
Co-Creation as an Enabler for Urban Innovation
}

\author{
Ingrid Mulder
}

extract richer insights about what drives people. Most living labs currently do not benefit from such a living methodology that enables the studying of social and dynamic interaction in the real world. Moreover, living methodologies are very heterogeneous and specific to the individual sites (and even vary within each site). In other words, "living methodologies" that relate to the assessment of social dynamics in real-life contexts on a large scale are still in their infancy. This is one of the main challenges for living labs: to mature living methodologies so that they can be used across living labs. Therefore, this article contributes to understanding of social experiences that make the living lab living and elaborates how living methodologies that capture social and dynamic aspects can be embedded in living lab practices.

We report on three living labs cases that were intended to enable the citizens of Rotterdam, Netherlands, to codevelop their city; our aim is to illustrate how living methodologies help us gain insights and activate users to design for tomorrow's society. The first case introduces visual ethnography as a research methodology that was used to improve the life of elderly citizens. The second case depicts prototyping as a method that helped to increase engagement in art co-creation among festival participants. The third case illustrates how living labs were used in co-creating new public services for the citizens and townspeople.

\section{Case 1: Visual Ethnography for Assisted Living}

There is a growing understanding that seniors should continue to function independently for as long as possible. Key to living independently is to promote solitude without added feelings of loneliness. Various ambient assisted living (AAL) development projects have taken place to empower seniors and to stimulate social connectedness. Still, these projects too often emphasize the introduction of innovative technologies that could be helpful in supporting elderly people in their daily lives, and they focus less on how existing and available technologies could fit their daily routines. One of our AAL projects aimed to advance videophone technology as a means to help independent elderly avoid social isolation (Goumans et al., 2012; tinyurl.com/9vj6969). We emphasised the elderly people's motivations for being social and investigated how they interact with the videophone in their own surroundings. We, therefore, used visual ethnography to study the elderly people's everyday lives in the chosen elderly residences.
Photos taken of daily living contexts proved to be helpful. For example, ageing comes with several barriers, such as changes in mobility, cognitive decline, and overall health problems, which all negatively influence social connectedness. The visual results of the observed elderly residence show that the design of the main entrance and the elevator are architectural issues that did not support successful ageing. The main entrance, for example, is an open space that does not provide any shelter from the rain or bad weather conditions, making the route unnecessarily slippery when wet. Our visual ethnography study thus revealed valuable insights that were not directly related to the use of videophone, but were necessary to comprehend the social context of elderly residents. These insights were crucial for understanding how new (and already available) technology could be embedded in residents' daily lives and in which ways it contributes to their independent living.

\section{Case 2: Prototyping for Increased Public Engagement}

The public space is the city's medium for communication with its citizens. Recent invasions of interactive media in the cityscape, however, are to a large extent commercial broadcasting systems that do not stimulate communication among citizens. The second example case originated from the idea that these emerging media can be interactive and used to enrich people's lives in a meaningful way. Aiming to stimulate more participation in the city and advance interaction among its inhabitants, we developed interactive art installations, which were used to prototype for public engagement by enhancing the physical world with the benefits of emerging media.

Prototyping was used as an informative design tool, as suggested by Suchman, Blomberg, and Trigg (2002; tinyurl.com/94ak7bs). Design tools are increasingly used to activate people enabling them to shape their own products, services, and living environments. With this example case, we illustrate how prototyping can be used to activate people, because one of the main challenges to keep living labs "living" is to involve active users in the product-service development. The interactive art installation was piloted in a real-life context during Rotterdam Museum Night (tinyurl.com/8cwas4r), a well-known cultural event that has been running for 10 years. In addition to over 50 museums remaining open all night long, the event includes numerous performances and exhibits by local artists lining the streets of 


\section{Co-Creation as an Enabler for Urban Innovation}

Ingrid Mulder

Rotterdam as visitors travel between museum sites. About 15,000 people visited the event in 2011.

Audience involvement was crucial in the interactive art installation; people visiting the event could shape the artwork together using a "magical cube" containing a motion-sensing video-game controller, through which sensory data was captured and then projected as video.
Interestingly, the audience was impressed, amazed, and even immersed by the video projection on the sculptures (Figure 1), though less interactivity among the engaged audience was observed. This may be due to that people were overwhelmed by the visual experiences and might not have been aware of the fact that they could interact with the sculpture and shape the artwork.
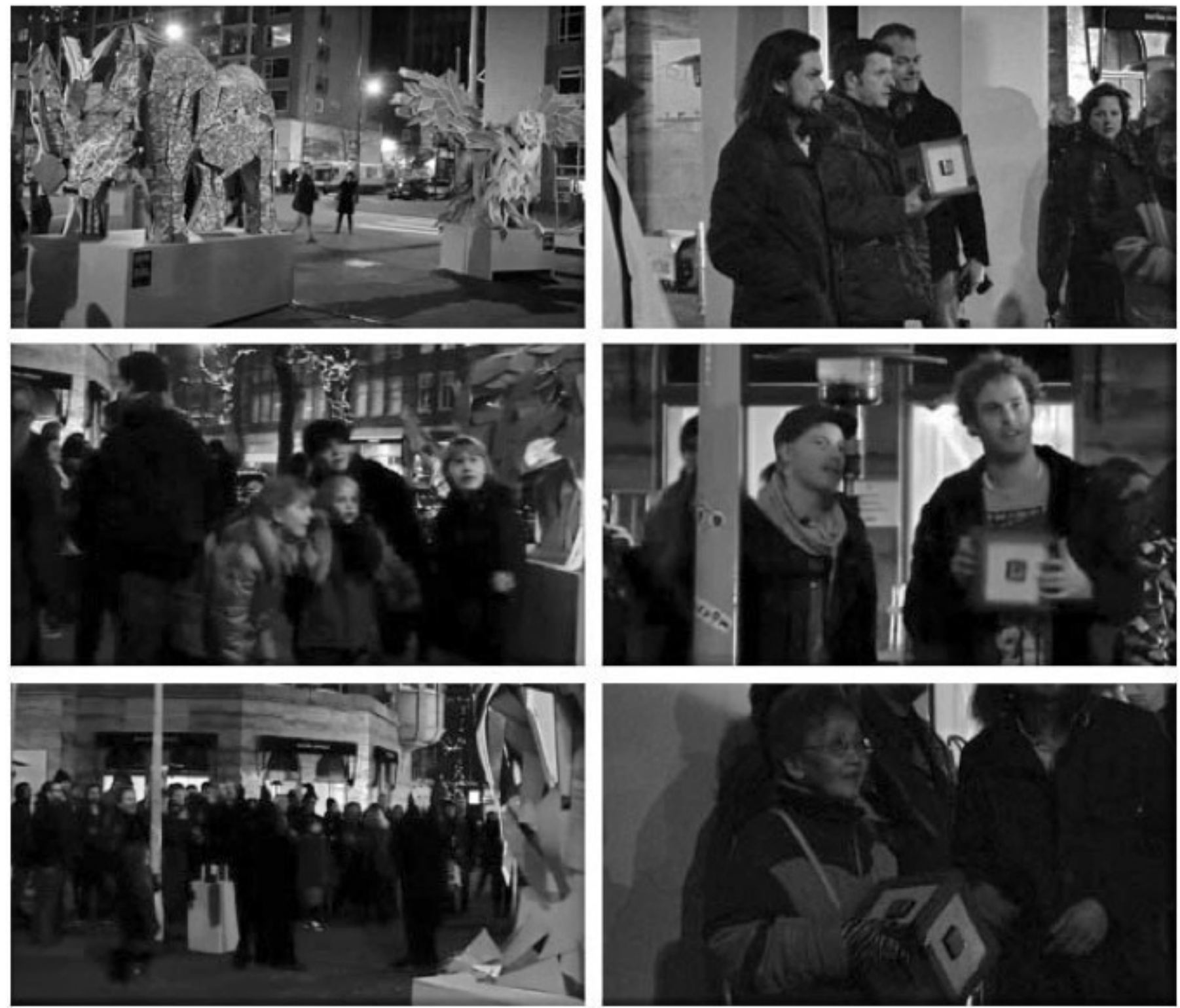

Figure 1. Impressions of the interactive art installation during the Rotterdam Museum Night 2011 


\title{
Co-Creation as an Enabler for Urban Innovation
}

\author{
Ingrid Mulder
}

\section{Case 3: Co-Creating Public Services Based on Open Data}

The core advantage of living labs methodologies over traditional user-centric methodologies is the contextual space in which the co-creation of ICT product and service development, and its evaluation, take place. With the third example, we illustrate co-creation in a real-life context. Public sector information (PSI) becomes open data when released into the public domain. Consequently, it is deemed suitable for re-use by citizens and available for the creative industry to build on and create new services. While the opportunities of opening up PSI are often referred to and supported by strategic mandates, the release of PSI by local governments is sometimes difficult. Since open data is not limited to the government as authority and the citizen as user, all public as well as private-sector living lab stakeholders participate together with local government, citizens, creative industry, and academia. We examined how such participation could be applied to PSI release leading to the co-creation of innovative public services that align with identified citizen needs. For details, see Conradie, Mulder, and Choenni (2012; tinyurl.com/9hyhpso).

Co-creation methods and storytelling were used to identify citizens' needs. These storylines then informed the public-service concept designs, to be created by student teams. These stories were also used as boundary objects enabling communication between citizens and the participating civil servants from the city council. Represented by seven participating city council services, each public service department started the project with a client briefing, in which goals or needs from the departments are presented. Ranging from curbing the social economic health differences in the region to making the core service of a particular council service more accessible to a younger or different target group, the goals acted as starting point for a co-creation design process led by students.

The co-creative efforts resulted in 36 public service ideas, varying in focus and maturity, though all focused on (re-)using PSI, which were presented during a national open data conference. After the conference, participants could vote for the winning concepts, and the alderman responsible for Employment, Education, Innovation, and Participation presented the top-five concepts. Some service concepts were taken into development, though the main outcome of the current pilot was to let these applications act as objects illustrating the value of co-creation and the potential of the reuse of open data.
The project not only provided many insights, but it also had a larger impact on open innovation in Rotterdam. The active participation and co-creation of multiple partners in the early phases of idea generation managed to put open data on the local policy agenda of the Rotterdam municipality. The board of management of the City Council decided to allow the release of the City Development Service's PSI as open data, having currently significant amounts of PSI available in an open data store for experimentation and co-creation of public services in Rotterdam. In addition, the project also introduced the participating creative-industry partners to the potential of using and re-using PSI and the important role of the creative industry in that endeavor. Citizens played a role by providing the input for the creation of the prototype applications, which in turn act as concrete examples to illustrate the benefit of the cooperation (Louwes, 2011; tinyurl.com/9kxj5aq)

By animating public servants to free up more PSI for reuse, potential fuel for other service design applications was created. The final event where applications were presented also acted as a platform where partners with different strategic backgrounds met and discussed the developed applications. The partnership between academia, the creative industry, and the public sector was awarded with additional research funding for two projects to further ensure the release of PSI.

By ensuring participation of the crucial partners, a sustainable infrastructure has been created to co-create public services and foster further innovation with PSI. The case example demonstrates that co-creation can also lead to the development of better public services, with citizens and the private sector contributing data by means of crowdsourcing, and it paves the way for more co-creation through open service development.

\section{Conclusion}

This article derived from the observation that existing living labs do not benefit from their full potential. Most living lab activities emphasize traditional user-centric lab methodologies, although it is the living part that makes a living lab an outstanding methodology for user-driven and co-creative innovation. Another observation was that the living methods and tools in common use are heterogeneous and vary between different living lab sites; they can even vary across the services within one site. This might not be a problem once living methods become harmonized, and tools could make it easier to compare findings across living labs and allow for a wider uptake of living methodologies. 


\section{Co-Creation as an Enabler for Urban Innovation}

\section{Ingrid Mulder}

The current article contributes to the use of living methodologies in understanding the social experiences that make the living lab living. It elaborates how these living methodologies, which capture social and dynamic aspects, can be embedded in the management of living labs. Three examples illustrated how the use of living methodologies contributes to gaining rich insights that are invaluable to inspire and inform the design of innovative services aiming to enrich our daily life and daily environment

Living methodologies as co-creation and visual ethnography as living methodologies enabled us to understand the social fabrics. Next, we ensured a sustainable social infrastructure for the development of open data and the related innovations that can be created as a result of an open data policy, going beyond merely the development of applications. Rich insights and prototypes are used as a form of inspiration and to inform social innovation and policymaking. On one hand, living labbing allows facilitation, and on the other hand, it facilitates participation. Living labbing enables co-creative practices in Rotterdam and has citizens shaping their own surroundings, thus making and co-designing the city of Rotterdam. The user-driven approach, do-it-yourself mindset, and the participatory character perfectly fit the down-to-earth Rotterdam attitude.

\section{Recommended Reading}

- The Living Labs Harmonization Cube:

Communicating Living Lab's Essentials

(Mulder et al., 2008; tinyurl.com/8su2mal)

\section{Acknowledgements}

The author is grateful to the researchers of Creating 010 and colleagues from RotterdamOpenData who contributed to the many constructive discussions in the city of Rotterdam. Special thanks go to Joke Mulder for her research on visual ethnography and to Bruce Moerdjiman for his work on interactive installations.

\section{About the Author}

Ingrid Mulder is Associate Professor of Design Techniques at ID-StudioLab, Faculty of Industrial Design Engineering, Delft University of Technology, and she is a research professor at Creating 010, Rotterdam University of Applied Sciences. She received her MA in Policy and Organization Sciences from the University of Tilburg, and she received her $\mathrm{PhD}$ degree from the University of Twente in the Faculty of Behavior Sciences. In 2005, she headed the evaluation of the first Dutch living lab, "Kenniswijk", which included over 116 innovative services experienced by 15,000 inhabitants having broadband Internet access. In the FP6 project CORELABS, she led the harmonization of methods and tools resulting in the establishment of the European Network of Living Labs. Her current research emphasizes open data, citizen participation, and responsible design for social cities of tomorrow.

Citation: Mulder, I. 2012. Living Labbing the Rotterdam way: Co-Creation as an Enabler for Urban Innovation. Technology Innovation Management Review. September 2012: 39-43. (cc) BY 